\title{
Portable Computing and the Networked Learner
} Wireless is nearly a Total Solution

\author{
C. Paul Newhouse \\ School of Education, Edith Cowan University, Perth, Western Australia \\ p.newhouse@cowan.edu.au
}

Keywords: laptop, networks, barriers, classroom teaching/practice

\begin{abstract}
The use of wireless networking with the latest portable computers may provide the solution to many technical and logistical problems faced by schools in facilitating the use of computers by students. This paper reports on an ethnographic action research study with the aim to investigate the potential of wireless networking in primary (elementary) schools. Data was collected about students, teachers and technology using formal interviews, observations of lessons, questionnaires, and informal discussions with teachers. The technology was successfully implemented with no significant technical problems supported by a mentoring approach to the professional development of teachers.
\end{abstract}

\section{INTRODUCTION}

The 'Holy Grail' in educational computing has been to provide access to adequate computer processing to support the learning of students wherever they are, whenever they need it and for whatever task it is needed. The reality now is that there are few technical barriers to these requirements (Becker, Ravitz and Wong 1999). The range of software available to support learning is vast and improving in quality to support almost any task we can imagine. The availability of sophisticated networking and powerful desktop and portable computers have provided the means of organising access to computer processing for students whenever it is needed. Finally, wireless networking has set the computer free to roam wherever it is needed by students. 
For at least two decades many researchers and national projects have investigated the use of computers in schools (e.g. Collis 1994, Gardner, Morrison, Jarman, Reilly and McNally 1994, Mandinach and Cline 1996). Educators have increasingly proclaimed the potential of computers in education to fulfil many of our aspirations. Consistently the finding has been that computer technologies have had little impact on schooling (Plomp and Pelgrum 1992). However, reports over the past few years appear to indicate that this situation is starting to change (Becker et al. 1999). To be realised critical changes will be required in curriculum, schools and classroom learning environments. Will these changes precipitate from the avalanche of computers into schools, particularly through schemes to provide one computer per student or must these changes occur before embarking on such schemes? While it is relatively safe to contend that most students in the future will have some form of portable computer processing, given the historically robust nature of schools it is difficult to predict in practice what impact this will have on schooling and the curriculum. Longitudinal research needs to be conducted at many school sites before any reasonable predictions can be made.

\section{FINDINGS FROM MY EARLIER RESEARCH}

The researcher was invited by the Principal of a secondary school to conduct an independent evaluation of the implementation of an initiative designed to encourage every student to have and use a portable computer to enhance their learning. As a result the researcher became immersed in the school community for a period of three years and collected a wide variety of data from students, teachers and the administrative records of the school. Four years later the researcher returned to collect follow-up data. Overall data were collected from over 60 teachers, 350 students (three cohorts of secondary students) and the observation of a large number of lessons (71 were analysed). Only a few of the findings of this large study can be alluded to in this paper.

\subsection{The adequacy and applications of the technology}

The Macintosh notebook-style computers appeared to be well matched to the needs of the students in terms of operation and portability, but not physical reliability. Although most models of computer used did not appear to be sufficiently robust, this in itself was not an inhibiting factor for either students or teachers. Students were inhibited by some features such as short battery life, perceived heaviness (if books required as well), and inadequate 
processing power and memory for some tasks. It was difficult to get access to the school's network and thereby the internet, since classrooms had at most one access point. Students had to connect via one of a handful of access points in the library or use a desktop computer. In the final year of secondary school about $50 \%$ of the students still had their portable computer (half of these boarded at the school).

Apart from in specialised computing classes, the computers were mainly used as writing tools (word processor) and for game playing. This concurs with the findings of many other researchers (e.g. Ainley, Bourke, Chatfield, Hillman and Watkins 2000). Occasionally subject specific applications such as Math Master ${ }^{\circledR}$ or MacGlobe ${ }^{\circledR}$ were used. In computing classes, students used a wider range of applications from databases and spreadsheets to Hypercard ${ }^{\circledR}$ and web-page production. In Year Eight (13 year old) the computers were typically used for about 3 hours per week at home and initially between 2 and 5 hours per week at school with an average of 8.4 hours per week in 1999. Year Twelve students (17 year old) estimated a mean of 3.7 hours per week using computers at home and almost none at school. For about $90 \%$ of these students only the word-processor and perhaps internet applications were used. In 1999 many Year Eight students mentioned applications such as spreadsheets for graphing, draw packages for graphics, internet applications and some multimedia presentation applications.

\subsection{Students' skills and attitudes}

One of the school's major aims was to increase the computer literacy of all students, common to many such programmes (e.g. Ainley et al. 2000). While to a large extent this was realised, most students developed skills in a haphazard way, relying on information gleaned from computer support teachers and other students, particularly those in computing classes. Students still required and expected more guidance and instruction in the efficient use of the machines and a better understanding of the underlying concepts. Irrespective of how well the programme was implemented it was likely that about $5 \%$ of the student population would have negative attitudes towards either the computers or their own competence in using the computers. Generally students were positive about the programme although many felt that teachers needed to facilitate more use of the computers. While there were increasingly positive outcomes for Year Eight students, particularly for those who were boarders, the experiences of many older students where the computers were rarely used, put them off using computers altogether.

Year Twelve students perceived the main benefit of having the computers to be the development of computer literacy for future work requirements and 
that this had largely occurred in Years Seven and Eight. They did not perceive the computers being a useful learning tool but felt that they needed to use the computers at home for word processing assignments, particularly for English. Over $90 \%$ indicated a reasonable level of computer literacy, $69 \%$ indicated they couldn't do without computers and $72 \%$ felt the programme had been a success. These perceptions should be very disturbing for the school since a computer literacy based on experiences four years previous is clearly inadequate and the relegation of such a powerful tool to typing up assignments and occasionally finding information on web-pages would seem extremely wasteful.

In 1999 the programme was seen as successful by all Year Eight students, even those who didn't like using the computers. The main benefits concerned the development of computer literacy and the easier and neater production of work. Most students used a commercial 'book on CDROM' for mathematics that they liked because it saved carrying the book around. There was still little if any mention of the computers being a useful learning tool but it was seen as a useful production tool and by some for accessing information. Some students felt that some of their classes had changed because they used their computers for 'everything'. The major problems were still the weight of carrying the computers and the high level of breakdowns. A number of students felt that they needed more systematic instruction on using their computers.

\subsection{The curriculum, teachers and learning environments}

Students were more likely to use the computers for classes associated with subjects such as English and social studies in which teachers required a substantial amount of document production. The computers were less likely to be used in classes with older, higher ability students than younger and/or lower ability students. This seemed to result from teachers' perceptions of the requirements of preparing students for tertiary entrance examinations. These examinations dominated the curriculum for most teachers and students, even in the lower secondary school. It was perceived that students needed to practice handwritten work in all subject areas to be prepared for these examinations. While there was little that could be done about the examinations themselves, further investigation should be conducted on the perceived link between using computers within the curriculum over the five years of secondary schooling and the performance of students in examinations.

In responding to the presence of the portable computers in a class, a teacher's actions could be classified into three broad types:

a) actively facilitates the use of the computers (Active), 
b) permits the use of the computers by those students choosing to do so (Passive), or

c) unconsciously or otherwise discourages the use of the computers (Negative).

Most teachers in 1995 typically responded in either Negative or Passive ways which limited the use of the computers. Only a few (about eight) usually responded in Active ways which is consistent with Becker's (1994) finding that only $5 \%$ of computer-using teachers are exemplary. His definition of such teachers would classify them as responding in an Active manner.

Many teachers were interested in facilitating the use of the computers but were not sure how to go about doing so with their classes. They did not want to be forced to use them but rather felt that they needed more examples of computer use applied to their area of the curriculum. Others did not see the computers as relevant to either their curriculum or their preferred teaching strategies. While many indicated a good level of computer literacy, a lack of operational knowledge of computers was still perceived by many as inhibiting their ability to facilitate students' use of the computers. The computers were not perceived as a necessary, or even critically useful, technology by almost all teachers. Clearly to support more than minimal use of the computers teachers need up to five years of experience in using computers in their learning programmes (Becker 1994),

Because of the minimal and limited use of the computers very few classes were observed in which the use of the computers made any sustained or major impact on the learning environment. Only those teachers who aimed to create classroom learning environments which promoted studentcentred learning (refer to Brady 1985) tended to regularly facilitate the use of the portable computers with their classes. Where teachers employed an instructivist pedagogy (refer to Reeves 1993), students were either required to use computers for only the limited role of a writing machine or were rarely required to use the computers at all. Some students left their computer at home when they did not think it would be needed. Research is increasingly supporting the notion that if computers are to be of significant value in classrooms, their introduction must be accompanied by a shift towards more student-centred teaching strategies (Dwyer, Ringstaff and Sandholtz 1991, Fishman and Duffy 1994, Hannafin and Savenye 1993)

\section{CURRENT RESEARCH}

Considering the results from these earlier studies the researcher decided to consider ways of addressing the technical, curriculum and pedagogical 
obstacles to using portable computers to support learning. Most of the curriculum obstacles concerned the rigidity of the curriculum and the dominance of the tertiary entrance exam. Therefore I decided to work within a government primary school where neither of these would be a factor. Secondly to overcome the pedagogical obstacles I decided to work with enthusiastic volunteers who were happy to utilise me as a mentor. Finally, to overcome the technical obstacles of weight, battery time, start-up time and network access I decided to work with Apple iBook computers with wireless networking.

The school had a class set (15) iBook portable computers with an AirPort Base Station. All classrooms had one or two ethernet port connections to the school's network which had internet connection. The AirPort Base Station may be plugged into the ethernet port in a classroom to provide network access for all the iBooks provided they are within about a 50 metre radius. The iBooks were kept in a specially designed trolley where they could be recharged while not in use (refer to Figure 1). All students had a workspace folder on the main network server which was password protected.

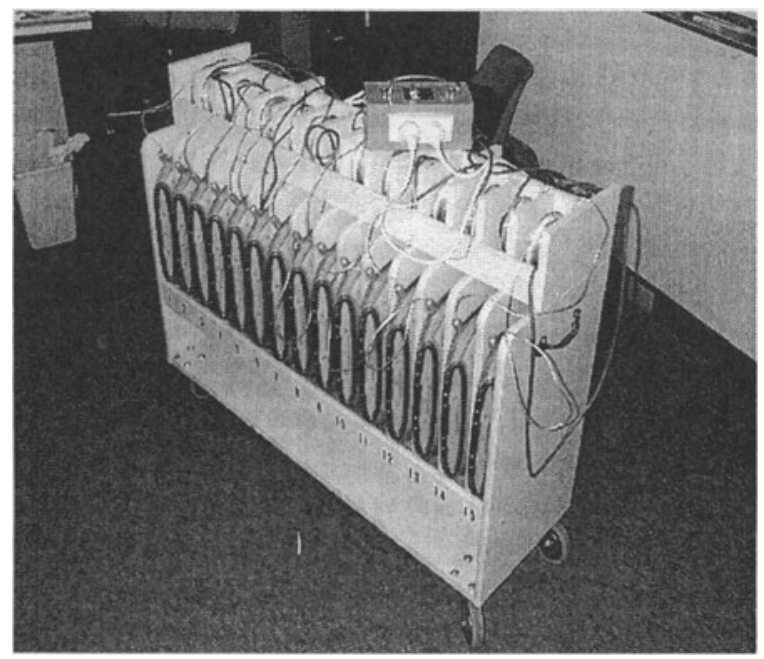

Figure 1. Purpose designed trolley with the iBooks ready to be charged.

During the year 2000 I conducted action research with two Year Seven classes and their teachers to investigate the use of wireless networking to support the use of computers in schools. This involved discussions with the teachers, observing the class, conducting a number of lessons and using questionnaires to conduct student surveys. In this paper I will briefly outline 
the first project on which the students worked with me as part of their drug education programme.

The project aimed to get the students, working in pairs, to collect and present information about one of the drugs: cannabis, tobacco, caffeine, or alcohol. The end result would be the creation of a slideshow presentation of their information which would be viewed by the other students and parents. Initially the students collected information from the library or from the internet, recording the information on a pre-designed A3 note-taking sheet under specific headings. In a number of sessions the students used the iBooks to access teacher-supplied web-sites. The students were shown how to save web-pages and graphic images from web-pages to their workspaces on the network server. At the same time the issues of copyright and referencing were addressed.

The teachers had not created slideshows before and therefore the I took on the task of showing the students how to use Microsoft Powerpoint to create slideshows and at the same time showing the teachers. In twol hour lessons the researcher worked with the students to create the slideshows. In the first lesson the students created slides, entered text into the outline, and selected a main slide design. I used the school's large monitor to demonstrate the features of a slideshow using one I had designed. In the second session the students inserted graphics and clip-art, and added transitions and effects. In a later lesson the students saved their slideshows as HTML, placed the folders into a common directory on the server which then acted as an intranet server (using the web-sharing MacOS facility). The students worked enthusiastically with each pair completing a slideshow. Towards the end of the project students started to consider questions of design and the implications of the information they had assembled.

To assist in focussing on the content the students had been asked to add a 'Questions' slide at the end of their slideshow to contain five questions to be answered by those who viewed their work. A week after the slideshows had been completed the students were required to view each others work and complete a content evaluation form which included answering the questions as well as a technical quality evaluation form for each presentation they viewed. After the completed evaluation forms had been viewed by the teacher they were returned to the designer of each presentation as feedback to allow for improvements to be made. The following week parents were invited to come in and view the presentations. There were some restrictions on when the students could use the computers because the lead teacher had many responsibilities in the school that meant he was not with his class (at least half of the time). Other teachers who took over the class were not involved with using the computers and did not feel confident enough to do so. 
From classroom observation it was found that all students were able to complete all the required tasks such as accessing a particular internet site, conducting a search, taking notes, saving web-pages and graphics, creating a slideshow and evaluating the work of other students. There were almost no technical problems with the computers and none with the access to networking via the AirPort wireless technology. Some students had explored extra features such as animations and it was clear from similarities in the final products that students often learned from each other.

The students indicated in a questionnaire that they were enthusiastic about using the computers and found the computers helped them. About $50 \%$ felt they had learned lots about drugs with all but one student indicating that they had learned some things about the drugs. About half preferred to work individually rather than in pairs but only 3 complained about sharing the computers. They found the computers most useful in creating the report, collecting the information and presenting the work to their teacher.

The teachers were enthusiastic about the results of the project and were keen to show off the work at the parents' night. They recognised that they had relied on the researcher for application ideas and skills in implementing those ideas. However, they felt confident enough to work with other teachers in the school on similar projects and began to do so. They began to think about what projects they could apply the computers to during the rest of the year. The relatively unrestricted curriculum of primary school education in Western Australia afforded them this luxury.

\section{CONCLUSIONS}

In my mind it is certain that in the near future most students in Australian schools will have access to some type of portable computing device (other than a calculator) most of the time. This will afford them access to a range of powerful applications, including networking applications. However, despite the removal of many of the technical barriers to provide this 'when and where needed' access it is still likely that there will be little impact on the learning experiences of most students. There remain many barriers to be overcome associated with school organisation, teacher skill, curriculum and pedagogy.

My research has found problems to overcome associated with the limited expertise and experience of most teachers and restrictions imposed by the curriculum and pedagogic organisation of the school. When the restrictions are removed and there is sufficient support for the teachers portable computers with wireless networking can readily support the constructivist learning environments many of us are striving to provide for students. 
Initially teachers need support in developing application ideas and skills in implementing those ideas. It is likely that a mentoring approach will be the most successful strategy to rapidly develop the necessary level of expertise and experience. These teachers may then become mentors for other teachers. The successful implementation of computers to support learning is now fundamentally dependent on teacher beliefs, attitudes, perceptions, experiences and skills rather than hardware and software characteristics.

\section{REFERENCES}

Ainley, M., Bourke, V., Chatfield, R., Hillman, K. and Watkins, I. (2000) Computers, Laptops and Tools. Australian Council for Educational Research, Melbourne.

Becker, H. J. (1994) How exemplary computer-using teachers differ from other teachers: Implications for realizing the potential of computers in schools. Journal of Research on Computing in Education, 26 (3), pp.291-321.

Becker, H. J., Ravitz, J. L. and Wong, Y. T. (1999) Teacher and Teacher-Directed Student Use of Computers and Software. (Teaching, Learning, and Computing: 1998 National Survey. No. 3). Center for Research on Information Technology and Organizations, University of California, Irvine, California.

Brady, L. (1985) Models and methods of teaching. Prentice-Hall, Sydney.

Collis, B. (1994) Triple innovation in the Netherlands. The Computing Teacher, 22 (2), pp. 23-26.

Dwyer, D. C., Ringstaff, C. and Sandholtz, J. H. (1991) Changes in teachers' beliefs and practices in technology-rich classrooms. Educational Leadership, 48 (8), pp. 45-52.

Fishman, B. J. and Duffy, T. M. (1994) Classroom restructuring: What do teachers really need? Education Technology Research and Development, 40 (3), pp. 95-111.

Gardner, J., Morrison, H., Jarman, R., Reilly, C. and McNally, H. (1994). Personal portable computers and the curriculum. (Practitioner Minipaper No. 13). Scottish Council for Research in Education, Glasgow.

Hannafin, R. D. and Savenye, W. C. (1993). Technology in the classroom: The teacher's new role and resistance to it. Educational Technology, 33 (6), pp. 26-31.

Mandinach, E. B. and Cline, H. F. (1996) Classroom dynamics: the impact of a technologybased curriculum innovation on teaching and learning. Journal of Educational Computing Research, 14 (1), pp. 83-102.

Plomp, T. and Pelgrum, W. J. (1992). Restructuring of schools as a consequence of computers. International Journal of Educational Research, 19, pp. 185-195.

Reeves, T. C. (1993) Interactive learning systems as mind tools. Viewpoints, 2, pp. 2-11.

\section{BIOGRAPHY}

For nine years Paul Newhouse taught in an innovative state secondary school in Western Australia working with pre-service and practising teachers in two universities. He is currently a lecturer at the School of Education at Edith Cowan University, Western Australia. 